\title{
Negative Regulation of Degradation of Complement
}

National Cancer Institute

\section{Source}

National Cancer Institute. Negative Regulation of Degradation of Complement. NCI

Thesaurus. Code C40684.

Complement Stabilization inhibits conjug ation, transport, oxidation, or proteolysis of complement system proteins; sequentially interacting serum proteins (some serine proteases), their receptors, and related regulatory proteins. Activated by cell-surface bound antibody, immune complexes, or a microbial membrane carbohydrate, complex complement cascades (classical or properdin pathway) generate Membrane Attack Complex, which creates target cell wall pores and lysis. The complement system also plays a role in antibody-dependent cytolysis, anaphylaxis, phagocytosis, opsonization, chemotaxis, and hemolysis. 